\title{
FINTECHS DE CRÉDITO E INTERMEDIÁRIOS FINANCEIROS: UMA ANÁLISE COMPARATIVA DE EFICIÊNCIA
}

\section{CREDIT FINTECHS AND FINANCIAL INTERMEDIARIES: A COMPARATIVE EFFICIENCY ANALYSIS}

\section{Emerson Faria}

Universidade de São Paulo - Faculdade de Economia, Administração, Contabilidade e Atuária.

\section{Liliam Sanchez Carrete}

Universidade de São Paulo - Faculdade de Economia, Administração, Contabilidade e Atuária.

\section{RESUMO}

Após a crise financeira global de 2008/09 iniciou-se uma forte onda de inovação na oferta de produtos e serviços financeiros por um novo tipo de empresa denominada FinTech (Finance e Technology, em inglês). Este trabalho comparou a eficiência das FinTechs com a dos bancos através de uma pesquisa de abordagem multi-métodos, qualitativa e quantitativa. Na primeira parte da pesquisa, de caráter qualitativa e exploratória, foram levantadas as principais similaridades e diferenças entre as FinTechs e os bancos. Na segunda parte, de caráter quantitativa descritiva, foi utilizada a técnica de análise comparativa com amostragem não probabilística, onde verificou-se que, na comparação com os bancos, as FinTechs possuem: (i) maior custo de intermediação financeira; (ii) maior despesa de intermediação financeira; (iii) maior relação despesas/receitas; e (iv) retorno negativo sobre o patrimônio líquido médio, cujos resultados acabaram não confirmando as inferências levantadas na primeira parte, que indicavam que as FinTechs são mais eficientes que os bancos, podendo ser explicado pelos seguintes fatores: (i) as FinTechs ainda não possuem o mesmo nível de maturidade dos bancos; e (ii) as FinTechs ainda não possuem escala suficiente para atingir os mesmos níveis de eficiência operacional dos bancos. Este trabalho buscou contribuir para que as FinTechs e os bancos encontrem suas melhores aptidões como modelo de negócio, melhorando a concorrência entre os 
agentes do sistema financeiro e resultando na oferta de produtos e serviços financeiros de forma mais justa e eficiente para a sociedade.

Palavras-chave: FinTech, crédito, bancos, intermediários financeiros, Peer-to-peer lending.

ABSTRACT

After the global financial crisis of 2008/09 started a new wave of innovation in the offering of products and financial services by a new type of startup denominated FinTech (Finance and Technology). This work compared the efficiency of FinTechs with the banks with a multi-method approach, through a research using both the qualitative and quantitative methods of research. In the first part of the research, under the qualitative exploratory approach, it was raised the main similarities and differences between FinTechs and banks. In the second part, under the quantitative descriptive approach, it was used the comparative analysis technique with a non-probabilistic sample, where was observed that, in comparison with the banks, FinTechs have: (i) higher cost of financial intermediation; (ii) higher expense with financial intermediation; (iii) higher cost/income ratio; and (iv) negative return on average equity, whose results did not confirm the inferences raised in the first part of the study, which suggested that FinTechs are more efficient than the banks, and can be explained by the following factors: (i) FinTechs still do not have the same level of maturity of the traditional financial intermediaries; and (ii) FinTechs still do not have enough scale to reach the same levels of operational efficiency of the traditional financial intermediaries. This work aimed to contribute for the FinTechs and banks to find their best aptitude as business model, improving the competition among the agents of the financial system and resulting in the offering of more fair and efficient financial products and services to the society.

Keywords: FinTech, credit, banks, financial intermediaries, Peer-to-peer lending.

JEL Classification: Insira aqui o JEL Classification do artigo. 


\section{INTRODUÇÃO}

A partir de 2008 o mundo parecia ter entrado em um estado de crise econômica global permanente. Vários notáveis economistas passaram a suportar essa ideia, tal como Gordon (2012), que afirmou que havíamos entrado em um estado de estagnação permanente. Esse pessimismo foi extensivamente debatido por analistas econômicos e financeiros por causa dos inúmeros escândalos que começaram a surgir, e suas consequências amplamente discutidas e até mesmo ironizadas, conforme a declaração do respeitado economista Paul Volcker, Presidente do Federal Reserve (Banco Central norte-americano) de 1979 a 1987 e Presidente do Conselho de Recuperação Econômica do Presidente Barack Obama de 2009 a 2011, de que a única inovação realmente útil ocorrida no mercado financeiro no último quarto do século 20 foi a criação da máquina ATM (Wall Street Journal, 2009). Durante esse período, alguns acadêmicos estudaram com mais profundidade esse tema e acabaram dando suporte à afirmação de Paul Volcker ao encontrar evidências empíricas de que a eficiência e a inovação na área financeira nas últimas décadas têm sido muito modestas, ou até mesmo inexistentes (Bazot, 2013; Philippon, 2015).

Por outro lado, após a crise financeira global de 2008/09 o mundo passou a observar uma forte onda de inovação na oferta de produtos e serviços financeiros, desde o surgimento de novos sistemas de pagamento (online e pelos celulares), de infraestrutura para transações financeiras (Blockchain) e empréstimos diretos entre as partes (peer-to-peer - P2P), até a criação de novas moedas globais, tais como o Bitcoin e o Brixton (Naqvi; Southgate, 2013). Usando uma combinação de uso extensivo de tecnologia, infraestrutura enxuta, foco no cliente e práticas flexíveis de negócios, essas novas empresas de tecnologia financeira denominadas FinTechs (contração dos termos Finance e Technology - Finanças e Tecnologia, em inglês) estão reduzindo o custo operacional dos serviços financeiros, ampliando sua base de clientes e ganhando participação de mercado de tradicionais empresas já estabelecidas na indústria financeira (Currencycloud, 2016).

Diante desse desafio, os bancos começaram a definir estratégias para responder às ameaças impostas por esses novos entrantes num mercado fortemente dominado por eles. Segundo a Consultoria Ernst \& Young (2015), os bancos 
aumentaram seus investimentos em Tecnologia da Informação, passaram a investir pesadamente no desenvolvimento de soluções bancárias digitais, e até mesmo na alocação de capital de risco em aceleradoras de startups, fizeram alianças estratégicas com algumas startups mais maduras e financiaram inovação em laboratórios especializados em finanças, embora ainda não seja clara a eficácia dessas ações.

Com a dificuldade enfrentada pelos bancos tradicionais em conseguir ganhar eficiência e inovar em produtos e serviços, um segmento de atuação dessas novas startups de tecnologia financeira que tem demonstrado força para competir diretamente com os bancos é o segmento de empréstimos peer-to-peer - P2P (direto entre as partes), que surgiram propondo novas formas de levantar capital para empresas e indivíduos, demonstrando forte capacidade de penetração no mercado, crescendo de forma rápida e ganhando força e relevância neste mercado (IYER et al., 2009). Uma dessas startups, a LendingClub, teve sua oferta pública inicial (IPO) realizada nos Estados Unidos em 2014, na Nasdaq, quando levantou US\$ 870 milhões de capital e foi avaliada em aproximadamente US\$ 8,9 bilhões. Valendo muito mais que inúmeros bancos tradicionais daquele país (Forbes, 2014), tornou-se uma das mais relevantes FinTechs de crédito.

Nos Estados Unidos, além da LendingClub, outras FinTechs de empréstimos P2P relevantes são a Prosper e a OnDeck (Letstalkpayments, 2015). Na Inglaterra, as mais relevantes são Zopa, RateSetter e Funding Circle (Techbullion, 2016). No Brasil também já existem algumas FinTechs ainda em estágio inicial, tais como Biva, Lendico, Geru, BankFácil, Simplic, Trigg e Nexoos (Valor Econômico, 2016).

Apesar de apresentar um futuro promissor, até o momento o segmento de empréstimos P2P ainda tem um histórico muito curto quando comparado com os intermediários financeiros tradicionais, mas independente disso, os bancos devem se preparar para um crescimento substancial desses novos competidores (INTERNATIONAL BANKER, 2015).

Embora hoje ainda não se saiba como a concorrência entre esses novos intermediários financeiros e os tradicionais irá se desenvolver, a relevância desse novo fenômeno e o impacto que ele poderá causar nos mercados financeiros ao redor do mundo são justificativas mais que plausíveis para que eles sejam estudados e melhor compreendidos daqui por diante, pois se por um lado parte da literatura questiona a 
capacidade intermediários financeiros tradicionais em se manterem no mercado em função de sua dificuldade de promover inovação e se adequar às necessidades dos novos usuários de serviços bancários, tais como as da geração Millenials (Haycock; Richmond, 2015), por outro lado outra parte acredita que as FinTechs assumiram o papel de introduzir inovações tecnológicas e apresentar novos modelos de negócio atuando em parceria com as instituições financeiras tradicionais, complementando os produtos e serviços oferecidos por elas (Li; Spigt; Swinkels, 2017; Cao, 2017).

\subsection{Problema da Pesquisa e Objetivo}

O problema da pesquisa deste trabalho reside na comparação da atividade de intermediação financeira praticada pelos bancos e pelas FinTechs de crédito, buscando entender as vantagens e desvantagens de cada modelo e compreender os aspectos relevantes dessa concorrência, e como isso poderá evoluir no médio e longo prazos, e se traduz na seguinte questão: "As FinTechs de crédito são mais eficientes que os intermediários financeiros tradicionais?"

Desse modo, além do objetivo principal de responder à pergunta acima, este trabalho também tem como objetivos secundários:

a) Levantar as similaridades e diferenças entre os dois modelos de negócio;

b) Diferenciar as vantagens e desvantagens de cada modelo de negócio; e

c) Comparar os aspectos determinantes da eficiência operacional dessas novas empresas com a dos intermediários financeiros tradicionais;

d) Identificar se a aptidão das FinTechs está mais para se tornarem concorrentes dos intermediários financeiros tradicionais ou se tornarem seus parceiros de negócio.

\section{REFERENCIAL TEÓRICO}

\subsection{Intermediação Financeira}

Para explicar o conceito de intermediação financeira, um exercício hipotético é considerar uma empresa que inclui em seus planejamentos a construção de uma planta de produção, mas que não tem os recursos para executar esse planejamento. Por outro lado, pode se considerar também um indivíduo que tenha recursos financeiros excedentes, mas não quer apenas deixar esses recursos guardados embaixo do colchão, mas gostaria de investi-los e assim obter um retorno financeiro sobre esses recursos. Pensando de forma lógica, bastaria à empresa (agente 
deficitário) que precisa de recursos procurar esse indivíduo (agente superavitário) com recursos excedentes e tomar emprestado a quantia necessária de recursos que ela precisa e fazer bom uso deles, e pagar um percentual sobre o valor emprestado, rentabilizando, assim, o agente superavitário. Porém não é isso o que acontece, e é justamente aqui que se torna relevante a figura do intermediário financeiro, que segundo Allen e Santomero (1998), possuem dois papéis bem distintos: facilitar a transferência de risco entre os agentes e lidar com o número cada vez maior de mercados e instrumentos financeiros.

Allen e Santomero (1998) também apontam as duas principais razões para a existência de intermediários financeiros:

a) Custos de transação;

b) Problemas decorrentes da assimetria de informação.

Em relação aos custos de transação, é muito difícil para o agente superavitário encontrar um agende deficitário que se encaixe ao perfil que ele procura para conceder um empréstimo de forma direta, e nessa procura incorrem custos de triagem, verificação, análise, monitoramento e aplicação das leis. Tanto agentes superavitários como agentes deficitários irão incorrer em custos de triagem para encontrar um ao outro, e em seguida o agente superavitário terá custos para verificar as informações fornecidas pelo agente deficitário, analisar seu perfil de risco, e depois que iniciar a operação, monitorar as atividades do agente deficitário. Por fim, ainda há os custos de aplicação das leis para certificar-se de que os pagamentos sejam feitos pelo agente deficitário nas datas previstas pelo contrato, ou conduzir um processo de recuperação da dívida nos tribunais, em caso de inadimplência. Gurley e Shaw (1960) afirmam que em relação aos custos fixos da avaliação de ativos, os intermediários financeiros têm vantagem sobre os indivíduos porque eles podem diluir esses custos com ganhos de escala.

A assimetria de informação ocorre quando uma das partes do contrato tem mais informação que a outra parte. Esse problema ocorre em todos os tipos de transações, não apenas as financeiras. Leland e Pyle (1977) sugerem que um investidor sinaliza seu status atual ao investir em ativos sobre os quais ele tem maior conhecimento. Diamond (1984) argumenta que os intermediários financeiros anulam o problema de assimetria de informação agindo como monitores constantes dos 
agentes. Outros autores que abordam as questões de assimetria de informação na intermediação financeira são Campbell e Kracaw (1980), Gale e Hellwig (1985) e Boyd e Prescott (1986). Sob o contexto de uma operação financeira, o agente deficitário que tomará os recursos emprestados sempre terá mais informações do que o agente superavitário em relação aos potenciais riscos e retornos do seu projeto de investimento no qual os recursos serão utilizados. A assimetria de informação resulta num problema para o agente superavitário, tanto antes da concessão do empréstimo, durante o processo de verificação das informações, como depois, durante os estágios de monitoramento.

O maior problema decorrente da assimetria de informação é o risco moral, que costuma ocorrer após a concessão do empréstimo, onde o tomador dos recursos começa a se envolver em atividades consideradas não-desejadas ou arriscadas demais sob a perspectiva do agente superavitário que concedeu o empréstimo, atividades essas que poderão comprometer a capacidade de pagamento do agende deficitário ao longo da operação. E em casos particulares, o agente deficitário poderá mudar seu comportamento assumindo mais riscos do que se estivesse utilizando apenas recursos próprios.

A questão chave deste momento é: como os bancos lidam com esses problemas? Bhattacharya e Shator (1993) explicam que os intermediários financeiros transformam ativos de alto risco e longo prazo que não se encaixam nos requerimentos dos agentes superavitários em certificados de depósito de baixo risco e prazos mais curtos que passam a se encaixar nesses requerimentos, e além das características de prazo e liquidez, eles também transformam as características de risco e volume dos contratos, através da aceitação de ativos de alto risco e em volumes específicos de acordo com os tomadores de empréstimo, e da emissão de certificados de depósito em volumes requeridos pelos agentes superavitários, bem como dentro do perfil de risco requerido por eles para emprestar seus recursos.

Intermediários financeiros reduzem os custos de transação através da expertise desenvolvida pela especialização da atividade que executam e através da economia de escala que conseguem obter devido ao seu tamanho e número de transações que conseguem executar simultaneamente (Allen; Santomero, 1998). De forma análoga, os 
intermediários financeiros também podem diversificar os custos de transação muito mais do que um indivíduo sozinho (Gurley; Shaw, 1960).

Os intermediários financeiros também podem reduzir os problemas oriundos da assimetria de informação e da seleção adversa através do desenvolvimento de expertise que os habilita a realizar uma boa análise de crédito e selecionar ativos com bom risco de crédito, tornando-se especialistas em analisar o crédito de indivíduos e empresas (Bhattacharya; Shator, 1993). Bancos têm uma vantagem particular nesse aspecto pelo fato de terem acesso a informações que um indivíduo, uma vez que eles têm acesso às informações das contas de seus clientes e do seu histórico bancário que outros agentes econômicos não têm.

\subsection{Eficiência bancária}

Apesar de ficar bem claro a razão da existência dos bancos e porque eles são bons em fazer o que eles fazem, há evidências de que está ocorrendo um declínio no cumprimento do papel tradicional dos bancos. Algumas das razões desse declínio são as reduções significativas dos custos de transação e da assimetria de informação nas últimas décadas (ALLEN; Santomero, 1998), que ao longo do tempo tem reduzido a importância dos bancos tradicionais que captam recursos através da emissão de certificados de depósito e concedem empréstimos. Allen e Santomero (1998) ainda apontam que um dos fatores que têm levado os bancos tradicionais ao declínio do seu papel é o surgimento de outros intermediários financeiros, tais como fundos de pensão, fundos mútuos de investimento e seguradoras, que tem aumentado significativamente sua participação no mercado financeiro: (i) a participação de proprietários individuais das empresas listadas na bolsa caiu de 85\% em 1967 para 52\% em 1995; (ii) a participação dos fundos de pensão, fundos mútuos de investimento e seguradoras no controle acionários das empresas listadas em bolsa aumentou de $15 \%$ em 1967 para 42\% em 1995. Além disso, outro motivo apontado por Allen e Santomero (1998) para o declínio dos bancos ao longo do tempo é o surgimento de produtos mais sofisticados: enquanto no final do século 19 e início do século 20 os principais instrumentos financeiros eram compostos em dívidas de longo, médio e curto prazo emitido pelos governos, certificados de depósito emitidos por bancos, ações e títulos de dívida de renda fixa de longo, médio e curto prazo emitidos por 
empresas, e contratos futuros de commodities negociados unicamente entre dois agentes específicos, a partir da segunda metade do século 20 surgem produtos tais como opções e contratos futuros de moedas, títulos securitizados e índices negociados nas bolsas de valores e mercadorias, swaps emitidos pelos bancos, permitindo que os agentes troquem o tipo de exposição a riscos com os bancos, e pelas empresas, títulos de dívida de taxa flutuante, indexados a algum tipo de taxa de juro, e títulos de renda fixa híbridos, como as debêntures conversíveis em ações.

Outro fator que tem levado os bancos ao declínio nas últimas décadas é a incapacidade de melhorar sua eficiência. Bazot (2013) e Philippon (2015), em estudos sobre a eficiência do sistema financeiro americano e europeu, respectivamente, demonstram que o custo unitário da intermediação financeira diminuiu somente de forma marginal após a crise de 2007/2009, e que a economia atingiu um nível de volume de crédito onde "mais recursos" não contribuem para melhorar a eficiência do sistema financeiro, e sinalizam que melhoras significativas de eficiência na atividade de intermediação financeira seriam possíveis apenas com a utilização de novas tecnologias e com a entrada de novos agentes de intermediação financeira.

Para medir o custo da intermediação financeira ao longo do tempo, em primeiro lugar Philippon (2015) definiu o modelo de mensuração do custo de intermediação financeira como a margem financeira do banco em uma operação bancária simples, conforme a Figura 1, abaixo:

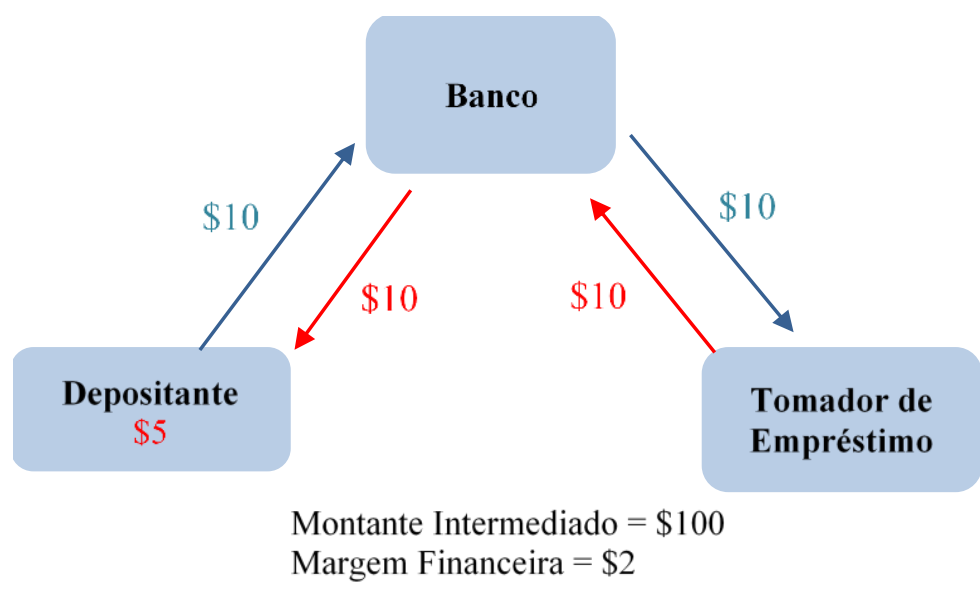

Figura 1 - Representação do modelo bancário simples de intermediação financeira Fonte: Phillipon (2015) 
Conforme a ilustração acima, que levou em consideração os spreads bancários praticados no mercado norte-americano, considerando que o banco pague $5 \%$ a um agente que faça um depósito pelo período de um ano, e que cobre $7 \%$ de um agente que tome um empréstimo também pelo período de um ano, ao final do período a margem financeira da operação que ficará retida no banco será de $2 \%$, aqui definido como o custo unitário de intermediação financeira, definido pela seguinte equação:

\section{Equação 1}

Custo Unitário da Intermediação Financeira = Margem Financeira / Volume da Operação

Onde:

a) $\quad$ Margem financeira $=$ receita financeira - despesa financeira;

b) Receita financeira = valor dos juros recebidos na operação;

c) Despesa financeira = valor das despesas incorridas na realização da operação;

d) Volume da operação = valor total do empréstimo feito na operação.

Desse modo, Philippon (2015) utilizou os dados das planilhas de cálculo do PIB norte-americano para mensurar a margem dos intermediários financeiros, o volume de investimentos, aplicações e empréstimos e calcular o custo unitário de intermediação financeira no período de 1886 a 2012, e verificou que este permaneceu entre $1,5 \%$ e $2,5 \%$ ao longo desse período (Figura 2 ), sendo que a média do período foi de $1,87 \%$.

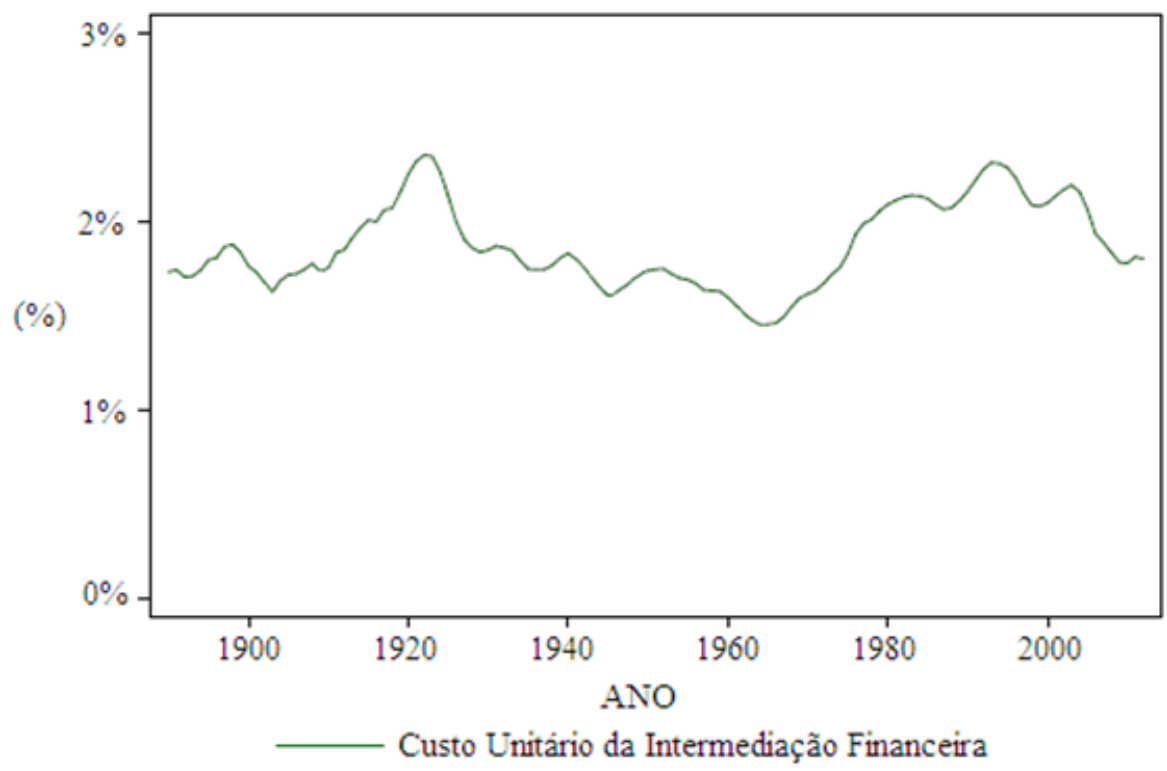


Figura 2 - Custo unitário da intermediação financeira nos Estados Unidos Fonte: Philippon (2015)

Bazot (2013) também realizou o mesmo estudo sobre o custo da intermediação financeira na Europa utilizando a mesma metodologia de Philippon (2015), mensurando o custo da intermediação financeira na Alemanha, França, Reino Unido, Espanha, Itália e Holanda, no período de 1951 a 2007, e comparou com os estudos de Philippon (2015), demonstrando que a custo médio unitário da Europa é muito similar aos dos Estados Unidos (Figura 3).

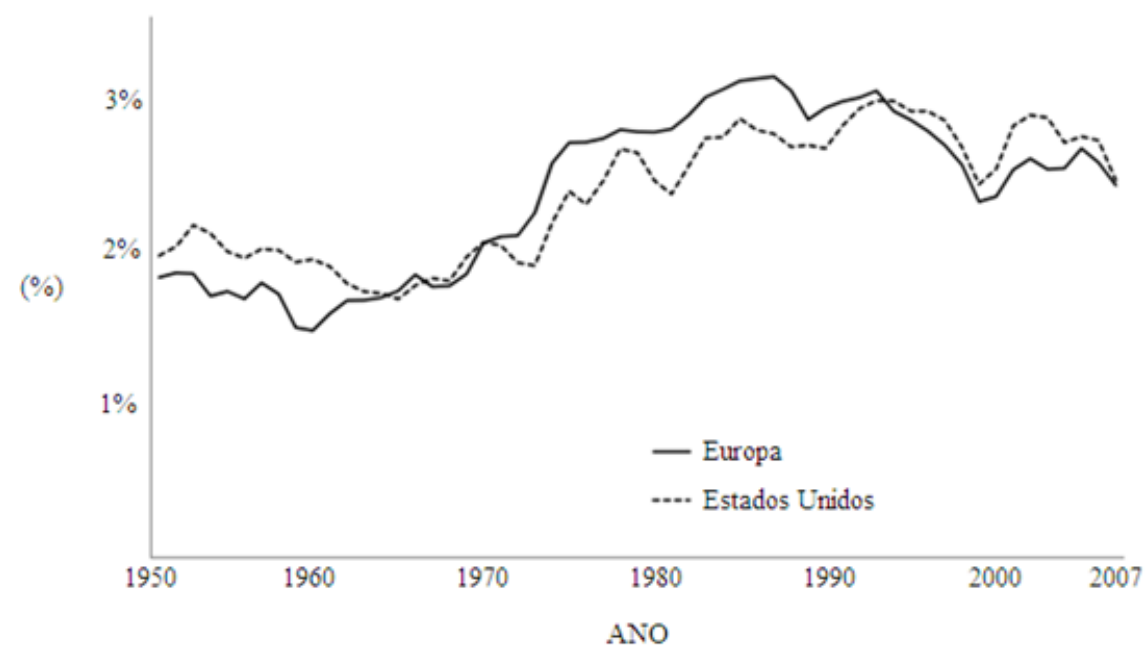

Figura 3 - Custo unitário de intermediação financeira na Europa e nos Estados Unidos Fonte: Bazot (2013)

Bazot (2013) e Philippon (2015) também observam que a evolução da tecnologia de informação aplicada às operações financeiras e os ganhos de eficiência do desenvolvimento dessas tecnologias não tem sido capazes de reduzir o custo unitário da intermediação financeira ao longo do tempo.

Um outro ponto relevante que tem contribuído para o declínio do papel dos bancos como intermediadores financeiros ainda relacionados com a incapacidade de aumentar a eficiência é a questão da concorrência entre os agentes do sistema financeiro. As barreiras à entrada de novos agentes e a baixa concorrência tem sido alguns dos problemas observados nos sistemas financeiros ao redor do mundo. Berger et al. (1999) analisam os impactos da consolidação bancária ocorrida nos Estados Unidos nos anos 90, quando o número de instituições financeiras diminuiu $30 \%$ entre 1988 e 1997 , resultando no aumento de $22,3 \%$ para $35,5 \%$ a fatia de mercado detida 
pelas oito maiores instituições financeiras no mesmo período. As principais razões para essa consolidação de mercado entre as instituições financeiras estão relacionadas ao ganho de poder de barganha, ao aumento da diversificação de produtos e à maior penetração de mercado. Berger et al. (1999) não encontram nenhuma evidência de ganho de eficiência dessas instituições após essas fusões e aquisições no mercado financeiro.

Wheelock (1993) também ressalta que embora os bancos ainda detenham o maior volume de ativos no sistema financeiro, eles têm perdido sua participação de mercado para novos tipos de intermediários financeiros entrando no mercado, uma vez que inovações tecnológicas em telecomunicações e sistemas de informação tem reduzido o custo das atividades relacionadas à análise de informações, facilitando a entrada de outros tipos de agentes nesse mercado.

\subsection{FinTechs}

Segundo Hochstein (2015), o primeiro registro de uso desse termo ocorreu no início dos anos 1990 pelo Citigroup, em um projeto chamado Financial Services Technology Consortium, cujo objetivo era promover o esforço conjunto entre instituições para facilitar a cooperação tecnológica. No entanto, apesar dos primeiros registros serem do início da década de 1990, o vínculo entre serviços financeiros e tecnologia financeira não é tão recente, e se desenvolveu ao longo de três períodos bem distintos entre si, de acordo com a definição de Buckley, Arner e Barberis (2016): o primeiro deles ainda está relacionado ao período totalmente analógico, onde ainda não existia nenhum recurso de tecnologia da informação; o segundo começa com a utilização dos primeiros recursos de processamento de dados aplicados à execução de operações financeiras, e acompanha o desenvolvimento da capacidade de processamento de informações; e desde 2008, observamos o surgimento do terceiro período dessa relação entre serviços financeiros e tecnologia da informação, ocasião em que o termo FinTech ganhou relevância e se tornou popular, apesar de já existir desde os anos 1990. Esse terceiro e mais recente período que iniciou a partir de 2008 não é mais caracterizado apenas pelos produtos e serviços financeiros, mas também por quem os fornece e pela aplicação da mais alta tecnologia disponível, tanto para os clientes de varejo como de atacado, sendo liderado por novas empresas 
extremamente inovadoras, que tem desafiado tanto os agentes econômicos tradicionais do mercado financeiro como os órgãos reguladores de todos os países com um sistema financeiro organizado.

A crise financeira global de 2008/09 causou uma forte mudança de mentalidade dos clientes de serviços financeiros, principalmente nas pessoas físicas, sobre quem tem os recursos e a legitimidade de fornecer serviços financeiros, uma vez que estes passaram a não confiar mais nos bancos como confiavam antes (Agarwal et al., 2014). Isso foi, sem dúvida alguma, um ponto de inflexão que funcionou como um catalisador para o surgimento desse terceiro período de relação entre os serviços financeiros e tecnologia da informação.

O século 20 foi caracterizado pela velocidade com que a tecnologia se desenvolveu, ou seja, basicamente pela velocidade dessa evolução, porém após 2008 essa evolução se caracteriza pelo surgimento de novos players altamente inovadores, produzindo uma série de novos aplicativos voltados para a entrega de serviços financeiros, concorrendo diretamente com os bancos, algo que nunca tinha ocorrido antes (Ferrari, 2016).

Em 2008 a imagem dos bancos e a percepção de estabilidade que eles passavam até então foram profundamente abaladas. Para se ter uma ideia de como isso evoluiu, em uma pesquisa realizada em 2015 pela publicação "Let's Talk Payments" sobre o nível de confiança das pessoas e nas empresas de tecnologia, entre outros resultados, enquanto apenas $37 \%$ declararam confiar no Citibank, $71 \%$ declararam confiar na Amazon e 64\% Google. Além de empresas já estabelecidas como Amazon e Google, existem milhares de startups que começaram a surgir a partir de 2008 que estão provendo serviços financeiros de forma muito mais eficientes e confiável do que os bancos. Mas como isso foi acontecer?

A crise de 2008/09 também causou forte impacto no mercado de trabalho, na demanda por crédito e na liquidez de recursos do sistema financeira global. Como primeiro impacto, destaca-se que entre os quase nove milhões de pessoas que perderam seus empregos, muitos deles eram profissionais altamente qualificados atuando na área de serviços financeiros, e os profissionais dessa área que não perderam seus empregos, de repente viram seus bônus por desempenho serem reduzidos à zero ou algo muito próximo disso, causando uma grande insatisfação entre 
eles (Esposito; TSE, 2014). O segundo impacto foi a forte queda da confiança da população nos bancos, e o terceiro impacto a retração da oferta de crédito, reduzindo fortemente a liquidez dos sistemas financeiros globais. A convergência desses impactos resultou no cenário perfeito para o surgimento de um novo setor financeiro, composto por empresas que passarão a formar esse terceiro período FinTech, que apesar de iniciarem suas atividades com poucos recursos, estavam em plena saúde e vigor financeiro, enquanto que os bancos estavam profundamente comprometidos com as perdas bilionárias oriundas do excesso de alavancagem que acabou resultando na crise de 2008/09. Em complemento ao cenário já descrito, temos também uma nova geração de recém-graduados, com alto nível de estudos e dificuldade em entrar no mercado de trabalho, também já com bom conhecimento e entendimento dos mercados financeiros (Fottrel, 2014), que passaram a ser recebidos de braços abertos pelas startups.

Outro desdobramento da crise de 2008/09 foi a imposição de uma forte carga de exigências e restrições regulatórias por parte dos Bancos Centrais aos participantes do Sistema Financeiro de cada país, resultando em um forte aumento nas despesas operacionais dos bancos devido às novas exigências para as áreas de Compliance das instituições financeiras, e também a uma redução dos orçamentos de pesquisa e desenvolvimento dessas instituições nos anos seguintes à crise, devido às restrições orçamentárias agravadas pelas perdas financeiras (MOSHIRIAN, 2011).

Segundo Dinardo (2016), os três fatores que permitiram às FinTechs promover uma ruptura nos modelos de negócios relacionados à prestação de serviços financeiros são os seguintes: i) avanço tecnológico, que permitiu à essas empresas oferecer soluções avançadas que influenciam o comportamento do consumidor e suas expectativas, em conjunto com uma série de mudanças de comportamento do próprio consumidor, com a popularização da internet e o surgimento dos smartphones, que estão revolucionando o modo como as pessoas e as empresas interagem entre si; ii) crise financeira global de 2008/09, que abalou fortemente a opinião pública em relação à solidez do sistema financeiro, levando os consumidores a adotar novos produtos e serviços oferecidos empresas apresentando novos modelos de negócios, em conjunto com a dificuldade das instituições financeiras tradicionais em conduzir adequadamente investimentos em tecnologia e inovação; e iii) regulação financeira, 
que após a crise financeira global de 2008/09 se tornou muito mais pesada e restritiva, tornando os bancos menos competitivos devido ao aumento dos custos relacionados às atividades de Compliance e à redução do orçamento para pesquisa e desenvolvimento.

\section{METODOLOGIA}

Esta pesquisa foi realizada a partir de uma abordagem multi-métodos, utilizando tanto a abordagem qualitativa como a quantitativa. A combinação de métodos pode ser feita por razões suplementares, complementares, informativas de desenvolvimento e outras, pois os paradigmas de pesquisa devem ser vistos como complementares (Corbin; Strauss, 2008).

A utilização dos dois métodos justifica-se pela validade e confiabilidade que se pretende dar à pesquisa. Eisenhardt (1989) argumenta que há sinergias ao se combinar metodologias qualitativa e quantitativa. A primeira permite entender a teoria que está por trás dos dados quantitativos, e esses últimos possibilitam identificar relações que podem não estar visíveis para o pesquisador que se utiliza somente de metodologia qualitativa.

Assim, visando atingir os objetivos deste trabalho, a pesquisa foi realizada em duas etapas. Na primeira etapa, de caráter qualitativo e exploratório, foi utilizada a técnica de entrevista para levantar as principais similaridades e diferenças entre as FinTechs e os intermediários financeiros tradicionais, seguido da diferenciação das vantagens e desvantagens de cada modelo de negócio, comparação dos aspectos determinantes da eficiência operacional das FinTechs e dos intermediários financeiros tradicionais, finalizando com a identificação da aptidão das FinTechs para serem concorrentes ou parceiros de negócio dos intermediários financeiros tradicionais. $\mathrm{Na}$ segunda etapa, de caráter quantitativo descritivo, foi utilizada a técnica de análise comparativa para se comparar as variáveis quantitativas das FinTechs com a dos intermediários financeiros tradicionais, e assim complementar a investigação feita na primeira etapa da pesquisa em relação um dos objetivos deste trabalho, o de comparar os determinantes da eficiência operacional das FinTechs e dos intermediários financeiros tradicionais. 


\section{ANÁLISE DOS RESULTADOS}

Os resultados obtidos na primeira parte da pesquisa atingiram os objetivos propostos, e indicaram que as FinTechs possuem um modelo de negócios mais eficiente que os intermediários financeiros tradicionais, cujas principais diferenças e vantagens em relação aos intermediários financeiros tradicionais ocorrem por se basearem em operações $100 \%$ digitais, terem um altíssimo nível de automatização dos processos, possuírem uma estrutura corporativa mais enxuta, manterem um baixo nível de burocracia, utilizarem as mais modernas tecnologias nos processos operacionais. Apesar disso, as FinTechs também possuem algumas similaridades com os intermediários financeiros tradicionais, tais como um modelo de negócios baseado em intermediação financeira, estrutura de custos e despesas concentrada em recursos humanos e tecnologia, estrutura de análise de crédito similar e modelo de precificação baseado em spread e taxa sobre serviços prestados. Por fim, se por um lado parte da literatura defende o fim dos bancos com o surgimento das FinTechs (Haycock; Richmond, 2015), por outro há autores que defendem que as FinTechs possuem o papel de introduzir inovações tecnológicas e novos modelos de negócio atuando em parceria com as instituições financeiras tradicionais, complementando os produtos e serviços oferecidos por elas (Li; Spigt;Swinkels, 2017; CAO, 2017), e ao final da primeira parte deste trabalho, observou-se que as FinTechs estão muito mais propensas a serem parceiras dos intermediários financeiros tradicionais do que seus concorrentes.

Na segunda parte da pesquisa, de caráter quantitativo descritivo, as FinTechs apresentaram os seguintes resultados na comparação com os intermediários financeiros tradicionais: (i) custo de intermediação financeiro mais alto (FinTechs entre $12,5 \%$ a.a. e 20,0 \% a.a. x Bancos entre 4,3\% a.a. e 4,8\% a.a.); (ii) despesas de intermediação financeira mais elevada (FinTechs entre 15,3\% a.a. e 20,6\% a.a. x Bancos entre 1,0\% a.a. e 3,3\% a.a.); (iii) maior relação despesas/receitas (FinTechs entre $119,1 \%$ e $129,4 \%$ x Bancos entre $63,2 \%$ e 68,7\%); e (iv) retorno negativo sobre o patrimônio líquido médio (FinTechs entre -11,9\% a.a. e -10,4\% a.a. x Bancos entre 3,8\% a.a. e $10,6 \%$ a.a.). Esses resultados podem ser explicados por dois fatores: (i) enquanto as FinTechs da amostra possuem menos de 10 anos de existência, os bancos possuem mais de 100 anos, alguns deles mais de 200 anos, indicando que o modelo de negócio das FinTechs talvez ainda não tenham atingido o nível de maturação necessária para se 
tornarem tão ou mais eficientes que os intermediários financeiros tradicionais; e (ii) as FinTechs ainda não alcançaram escala suficiente para atingir os níveis de eficiência operacional potenciais desse modelo de negócio, a ponto de serem tão ou mais eficientes que os intermediários financeiros tradicionais.

\section{CONSIDERAÇÕES FINAIS}

Considerando-se os resultados empíricos obtidos neste trabalho, verificou-se que não é possível apresentar uma resposta conclusiva à questão da pesquisa, pois ao mesmo tempo em que foram levantadas fortes evidências qualitativas de que as FinTechs podem ser mais eficientes que os intermediários financeiros tradicionais, as evidências quantitativas não confirmam as inferências levantadas na primeira parte da pesquisa, que pode ser explicado pelos seguintes fatores: (i) as FinTechs ainda não possuem o mesmo nível de maturidade dos bancos; e (ii) as FinTechs ainda não possuem escala suficiente para atingir os mesmos níveis de eficiência operacional dos bancos. Desse modo, essas razões poderão ser esclarecidas ao longo do tempo, conforme esse novo modelo de negócio se amadurecer e ganhar escala.

Em face dos resultados desta pesquisa, espera-se contribuir para que a sociedade possa entender um pouco mais sobre o modelo de negócios das FinTechs, identificando as similaridades e diferenças, assim como as vantagens e desvantagens, desses novos entrantes no competitivo mercado financeiro global em relação aos velhos incumbentes desse sistema, e assim, cada modelo de negócios possa encontrar sua melhor aptidão, melhorando a concorrência entre os agentes do sistema financeiro e resultando na oferta de produtos e prestação de serviços financeiros de forma mais justa e eficiente para a sociedade em geral.

Para a expansão do conhecimento sobre a comparação da eficiência entre as FinTechs e os intermediários financeiros tradicionais, recomenda-se para futuras pesquisas envolvendo indicadores de eficiências entre esses dois modelos de negócio, aumentar o período de análise dos dados, após as FinTechs amadurecerem mais seus modelos de negócio e adquirirem maior escala operacional. Esse procedimento poderá gerar condições para se realizar uma análise com menos distorções de indicadores. Da mesma forma, recomenda-se também aumentar a amostra do estudo, o que será 
possível apenas com o passar do tempo, pois só assim a amostra de dados com as informações necessárias para a pesquisa poderá ficar mais robusta.

\section{REFERÊNCIAS}

AGARWAL, S. et al. Inconsistent Regulators: Evidence from Banking. Quarterly Journal of Economics 129, p. 889-938, Oxford, 2014.

ALLEN, F.; SANTOMERO, A. M. The Theory of Financial Intermediation. Journal of Banking and Finance 21. 1461-1485, Amsterdam, 1998.

BAZOT, G. Financial consumption and the cost of finance: Measuring financial efficiency in Europe (1950-2007). Working Paper Paris School of Economics, Paris, 2013.

BERGER, A. N.; DEMSETZ, R. S.; STRAHAN, P. E. The consolidation of the financial services industry: causes, consequences, and implications for the future. Journal of Banking and Finance 23, 94-135, Amsterdam, 1999.

BHATTACHARYA, S.; THAKOR, A. V. Contemporary Banking Theory. Journal of Financial Intermediation 3, 2-50, Amsterdam, 1993.

BOYD, J.; PRESCOTT, E.C. Financial intermediary coalitions. Journal of Economic Theory 38, 211-232, Amsterdam, 1986.

BUCKLEY, R.; ARNER, D. W.; BARBERIS, J. N. The Evolution of Fintech: A New PostCrisis Paradigm? Georgetown Journal of International Law. 47. 1271-1319, Georgetown, 2016.

CAMPBELL, T.S.; KRACAW, W.A. Information production, market signaling, and the theory of financial intermediation. Journal of Finance 35, 863-882, New Jersey, 1980.

CAO, L. Fintech and the future of Financial Services. CFA Institute, Charlotesville, 2017.

CORBIN J.; STRAUSS, A. Pesquisa Qualitativa: técnicas e procedimentos para o desenvolvimento de teoria fundamentada. 2a ed. Porto Alegre. Artmed, Porto Alegre, 2009.

CURRENCYCLOUD REPORT. Banks and the FinTech Challenge: How disruption has been a catalyst for collaboration and innovation, 2016. Disponível em < https://www.currencycloud.com/files/2016-Banks.and.the.Fintech.Challenge.pdf $>$. Acesso em 15 abr. 2017. New York, 2016.

DIAMOND, D. Financial intermediation and delegated monitoring. Review of Economic Studies 51, 393-414, Oxford, 1984. 
DINARDO, F. The rise of alternative finance: How Fintech companies are revolutionizing the financial services and the traditional bank financing. Tese de Mestrado. Universitita' Degli Studi Di Padova, Padova, 2016.

EISENHARDT, K. M. Building Theories From Case Study Research. The Academy of Management Review, v. 14, n. 4, 535-550, New York, 1989.

ERNST \& YOUNG. Fintech: Are banks responding appropriately? 2015. Disponível em < http://www.ey.com/Publication/vwLUAssets/EY-fintech-are-banks-responding-

appropriately/SFILE/EY-fintech-are-banks-responding-appropriately.pdf > Acesso em 15 abr. 2017. London, 2015.

ESPOSITO, M.; TSE, T. The lost generation: what is true about the myth... The London School of Economics and Political Science, 2014. Disponível em < http://blogs.Ise.ac.uk/eurocrisispress/2014/04/07/the-lost-generation-what-is-trueabout-the-myth/ >. Acesso em 12 fev. 2017. London School of Economics, London, 2014.

FERRARI, R. FinTech Impact on Retail Banking - From a Universal Banking Model to Banking Verticalization. The Fintech Book. Wiley, New Jersey, 2016.

FORBES. LendingClub and Billion-Dollar Valuations are just the Beginning for Online Lending, $2014 . \quad$ Disponível em < https://www.forbes.com/sites/navathwal/2014/12/18/lendingclub-ondeck-iposbillion-dollar-valuations-are-just-the-beginning-for-the-online-lendingmarket/\#46c5fb415df1 >. Acesso em 15 abr. 2017. New York, 2014.

FOTTREL, Q. Millenials are the most underemployed generation. MarketWatch, 2014. Disponivel online em < http://www.marketwatch.com/story/millennials-are-the-mostunderemployed-generation-2014-11-19 >. Acesso em 12 fev. 2017. New York, 2014.

GALE, D.; HELLWIG, M. Incentive-compatible debt contracts: The one-period problem. Review of Economic Studies 52, 647-664, Oxford, 1985.

GORDON, R. 'Is US Economic Growth Over? Faltering Innovations Confronts the Six Headwinds', NBER Working Paper n. 18315, Cambridge, 2012.

GURLEY, J.G.; SHAW, E.S. Money in a Theory of Finance. Brookings Institution, Washington, 1960.

HAYCOCK, J.; RICHMOND, SHANE. Bye Bye Banks?: How Retail Banks are Being Displaced, Diminished and Disintermediated by Tech Startups - and What They Can Do to Survive. Wunderkammer, Bath, 2015.

HOCHSTEIN, M. Fintech (the Word, That Is) Evolves. American Banker, 2015. Disponível em: < https://www.americanbanker.com/opinion/fintech-the-word-that-isevolves >. Acesso em: 12 fev. 2017. New York, 2015. 
INTERNATIONAL BANKER. Peer-to-Peer Lending - Disruption for the banking sector? 2015. Disponível em < https://internationalbanker.com/banking/peer-peer-lendingdisruption-banking-sector/ >. Acesso em 15 abr. 2017. Dublin, 2015.

IYER, R.; KHWAJA, A. I.; LUTTMER, E. F.; SHUE, K. Screening in New Credit Markets: Can Individual Lenders Infer Borrower Creditworthiness in Peer-to-Peer Lending? Working Paper, Kennedy School, Harvard University, Boston, 2009.

LELAND, H.E.; PYLE, D.H. Informational asymmetries, financial structure, and financial intermediation. Journal of Finance 32, 371-387, Wiley, New Jersey, 1977.

LETSTALKPAYMENTS. Survey Shows Americans Trust Technology Firms More Than Banks and Retailers, 2015. Disponível em < https://letstalkpayments.com/surveyshows-americans-trust-technology-firms-more-than-banks-and-retailers/ >. Acesso em 12 fev. 2017. New York, 2015.

LETSTALKPAYMENTS. US Peer-to-Peer (P2P) Lending Market: A Sector Snapshot, 2015. Disponível em < https://letstalkpayments.com/us-peer-to-peer-p2p-lendingmarket-a-crisp-report/ >. Acesso em 15 abr. 2017. New York, 2015.

LI, Y.; SPIGT, R.; SWINKELS, L. The impact of FinTech start-ups on incumbent retail banks' share prices. Financial Innovation (2017) 3:26, Springer Open, London, 2017.

MOSHIRIAN, F. The global financial crisis and the evolution of markets, institutions and regulation. Journal of Banking \& Finance, v. 35, Issue 3, Amsterdam, 2011.

NAQVI, M.; SOUTHGATE, J. Banknotes, local currencies and central bank objectives. Bank of England Quarterly Bulletin 2013 Q4, v. 53, n. 4, p. 317-325, London, 2013.

PHILIPPON, T. Has the US finance industry become less efficient? On the theory and measurement of financial intermediation. The American Economic Review 105(4), 1408-38, Washington, 2015.

TECHBULLION. Major Players in the US P2P Lending Market, 2016. Disponível em < http://www.techbullion.com/major-players-uk-p2p-lending-market/ >. Acesso em 15 abr. 2017. London, 2016.

VALOR ECONÔMICO. Associação busca modelo com credibilidade, 2016. Disponível em < https://www.pressreader.com/brazil/valorecon\%C3\%B4mico/20161125/282316794639897 > Acesso em 15 abr. 2017. São Paulo, 2017.

WALL STREET JOURNAL.Volcker Praises the ATM, Blasts Finance Execs, Experts, 2009. Wall Street Journal, 08 dez. 2009. Disponível em < http://blogs.wsj.com/marketbeat/2009/12/08/volcker-praises-the-atm-blasts-financeexecs-experts/ >. Acesso em 15 abr. 2017. New York, 2009. 
WHEELOCK, D. Is the Banking Industry in Decline? Recent Trends and Future

Prospects from a Historical Perspective. Federal Reserve Bank of St. Louis Review, 75 (5). 3-22, 1993. Saint Louis, 1993. 